\title{
Effects of Sintering Temperature and Holding Time on Densification and Mechanical Properties of MIM HK30 Stainless Steel
}

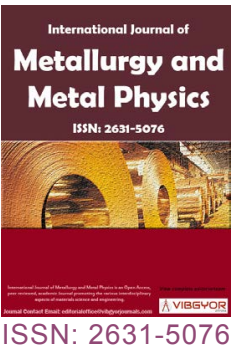

\section{Youhua $\mathrm{Hu}^{1}$, Yimin $\mathrm{Li}^{2}$, Jia $\mathrm{Lou}^{3}$, Hao $\mathrm{He}^{2}$ and Xiang Zhang'}

${ }^{1}$ State Key Laboratory of Powder Metallurgy, Central South University, China

${ }^{2}$ Research Centre for Materials Science and Engineering, Guangxi University of Science and Technology, China

${ }^{3}$ School of Materials Science and Engineering, Xiangtan University, Xiangtan, China

\begin{abstract}
The sintering process of HK30 stainless steel (SS) prepared by metal injection molding (MIM) was studied. The effects of the sintering temperatures $\left(1270,1280\right.$, and $\left.1300^{\circ} \mathrm{C}\right)$ and holding times $(1,3,5,7$, and $9 \mathrm{~h})$ on the densification, microstructure, and mechanical properties were investigated. To achieve a stable high performance, the sintering process should be carried out at $1280^{\circ} \mathrm{C}$ for $7 \mathrm{~h}$. The obtained density, micro-hardness, tensile strength, and elongation are $7.61 \mathrm{~g} / \mathrm{cm}^{3}, 187 \mathrm{HV}_{1.0}, 570 \mathrm{MPa}$, and $31 \%$, respectively, attaining the standard of forged HK30 SS. The average grain size of the samples is $64 \mu \mathrm{m}$. In addition to the grain growth, the higher sintering temperature of $1300^{\circ} \mathrm{C}$ led to over-heating or over-burning, which reduced the bonding strength between grain boundaries. As a result, the density and mechanical properties decreased.
\end{abstract}

\section{Keywords}

Metal injection molding, HK30 stainless steel, Densification, Microstructure, Mechanical properties

\section{Introduction}

Powder injection Molding (PIM) is a powder metallurgy (PM) near-net-shape-forming process that has been rapidly developing in recent years $[1,2]$. It involves four steps: (i) Feedstock preparation by mixing powders (metals or ceramics) and binders; (ii) Injection of the feedstock; (iii) De-binding of the injected parts (green parts), and (iv) Sintering of the de-bound parts (brown parts). When a metal powder is used, the process is called metal injection molding (MIM) [3-5]. MIM has been successfully applied in the production of low-alloy steel, stainless steel, super alloys, and other alloy systems.

HK30 SS is a widely used heat-resistant austenitic stainless steel. It is a type of alloy with a high strength, oxidation resistance, and corrosion resistance at $600-1000^{\circ} \mathrm{C}$, and is commonly used for

*Corresponding author: Yimin Li, State Key Laboratory of Powder Metallurgy, Central South University, 410083, Changsha, China

Accepted: October 23, 2018; Published: October 25, 2018

Copyright: (c) $2018 \mathrm{Hu}$ Y, et al. This is an open-access article distributed under the terms of the Creative Commons Attribution License, which permits unrestricted use, distribution, and reproduction in any medium, provided the original author and source are credited.

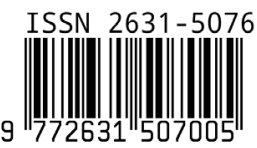

Hu et al. Int J Metall Met Phys 2018, 3:022 
Table 1: Chemical composition of SS powder.

\begin{tabular}{|l|l|l|l|l|l|l|l|l|}
\hline Element & $\mathrm{Cr}$ & $\mathrm{Ni}$ & $\mathrm{Nb}$ & $\mathrm{C}$ & $\mathrm{O}$ & $\mathrm{Si}$ & $\mathrm{Mn}$ & $\mathrm{Fe}$ \\
\hline Mass ratio (\%) & 25.1 & 20 & 1.31 & 0.32 & 0.13 & 0.93 & 0.98 & Bal. \\
\hline
\end{tabular}

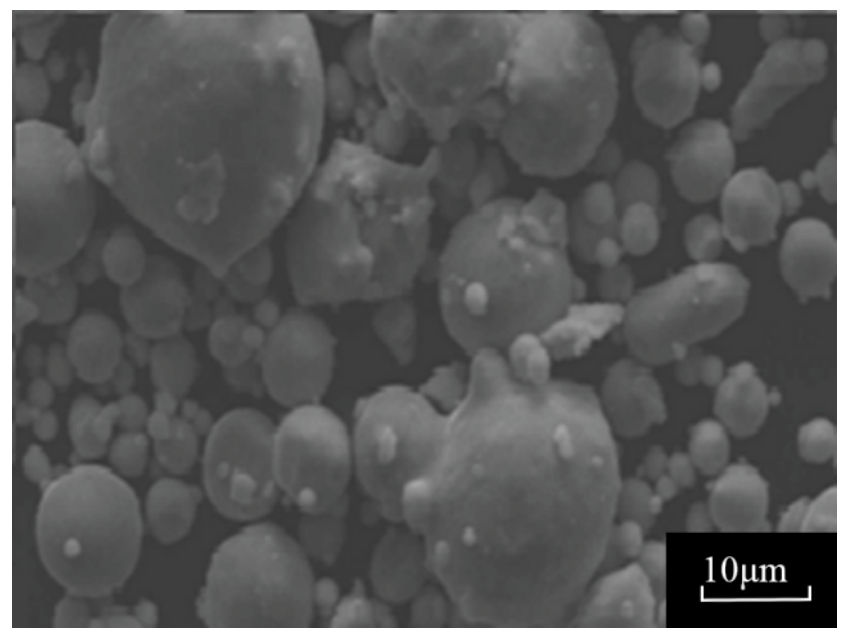

Figure 1: Morphologies of HK30 SS powders.

turbocharger vanes [6-11]. However, in the PM process, sintering is difficult because a relatively low temperature $\left(<1300^{\circ} \mathrm{C}\right)$ and a long holding time (4-8 h) are employed, compared with the sintering temperature of approximately $1350{ }^{\circ} \mathrm{C}$ and holding time of 2-3 $\mathrm{h}$ for $316 \mathrm{LSS}$. Furthermore, the obtained density is only $92-95 \%$ of the theoretical density, which is lower than the $\geq 97 \%$ for $316 \mathrm{~L}$. A higher temperature leads to over-burning and significant grain growth.

As a result, specific attention has been paid to the sintering of MIM HK30 [12-16]. Wang, et al. studied all the MIM process steps of HK30 SS, including feedstock preparation, injection molding, de-binding, and sintering [17]. Shen, et al. studied the surface over-burning phenomenon of the sintered HK30 sample [18]. Li, et al. suggested that adding Ti to MIM HK3O can accelerate the densification rate and decrease the sintering activation energy but is harmful to the austenite hardness [19]. Zhang, et al. studied the effect of carbon content on the sintering properties of MIM HK30 and recommended a carbon content of 0.18 [20]. The effects of powder size and sintering atmosphere on the mechanical properties of MIM HK3O were studied by Kearns, et al. [6]. However, few research studies focused on the HK30 sintering window, and hence, there is a lack of a systematic study on the combined influence of the sintering temperature and holding time.

In this study, sintering of MIM HK30 was carried

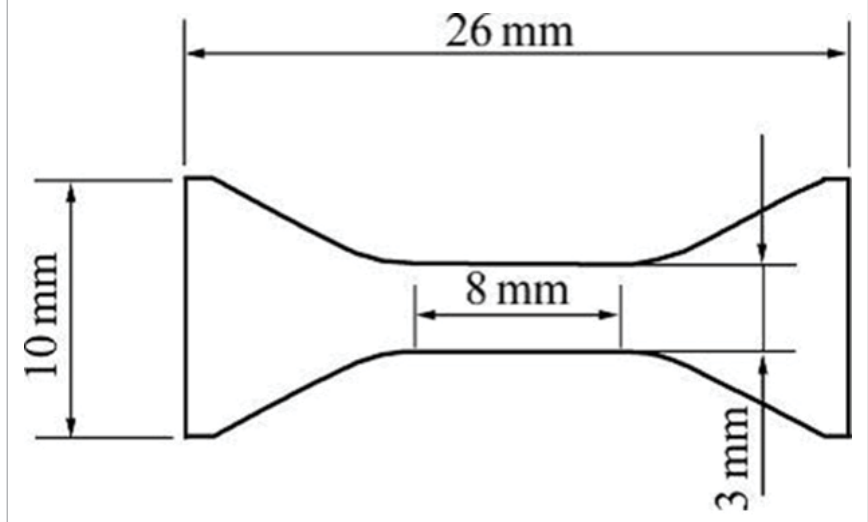

Figure 2: Sketch of the tensile sample.

out at different temperatures and holding times. The effects of the sintering conditions on the sintering properties and mechanical properties were analyzed. The optimum sintering process for MIM HK30 is suggested. This is of practical significance to guide the actual production of MIM HK30 products.

\section{Experimental Procedures}

The tested gas-atomized HK30 SS powders were provided by Sandvik Osprey Ltd. The particle morphologies of the powder are shown in Table 1 and Figure 1. The particle size distribution is as follows: $\mathrm{d}_{10}=4.1 \mu \mathrm{m}, \mathrm{d}_{50}=12.3 \mu \mathrm{m}$, and $\mathrm{d}_{90}=26.7 \mu \mathrm{m}$. The main components of the binder are paraffin wax $(P W)$, stearic acid (SA), polypropylene (PE), and vegetable oil; this was mixed with the SS powder, and the powder loading was 58 vol\%. The tensile samples were prepared by injection molding, after mixing and pelletizing. The size of the tensile sample is shown in Figure 2. The solvent de-binding was performed by immersing the compacts in methylene chloride at $36^{\circ} \mathrm{C}$ for $6 \mathrm{~h}$. Then, thermal de-binding was carried out under argon atmosphere with a flux of $5 \mathrm{~L} / \mathrm{min}$ at $800{ }^{\circ} \mathrm{C}$, maintained for $1 \mathrm{~h}$. Sintering was performed at 1270, 1280, or $1300{ }^{\circ} \mathrm{C}$ with different holding times under argon atmosphere.

The density of the sample was measured by the Archimedes method, and the microstructure of the material was observed using a Polyvar Met metalloscopical microscope. The grain size was measured according to the ASTM E112-2013 standard [21]. The average number of grains per $\mathrm{mm}$ was determined by counting the number of grains intercepted on a $1 \mathrm{~mm}$ - long line. The average value was determined using 10 measured values in 


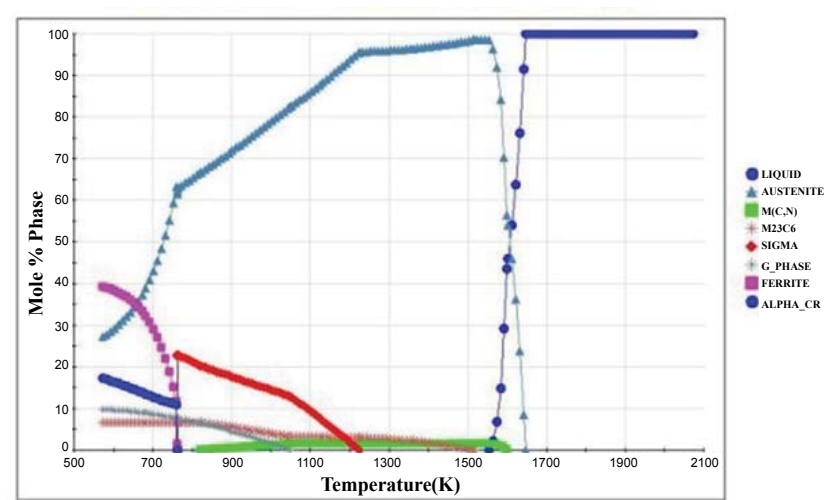

Figure 3: Thermo-Calc simulation picture of HK30 SS.

the observed field. The hardness was tested using a MicroMet-5140 micro-hardness instrument, and the average value of each sample was calculated from at least 10 points. The tensile strength and elongation of the material were measured using an Instron universal tester, and the tensile speed was $2.0 \mathrm{~mm} / \mathrm{min}$. The tensile fracture morphology was observed using a JSM-6360 scanning electron microscope.

\section{Results and Discussion}

\section{Simulation of sintering densification process of HK30 using Thermo-Calc}

To identify the phase transformation that will take place during the sintering process, the phases and their mole ratios at different temperatures of HK30 were simulated using the Thermo-Calc software, as shown in Figure 3. This shows that the liquid phase appears at about $1553 \mathrm{~K}\left(1280^{\circ} \mathrm{C}\right)$, during the sintering process of HK30. Therefore, the sintering temperature should be set near $1280{ }^{\circ} \mathrm{C}$ to obtain a supersolidus liquid sintering effect. Supersolid phase sintering is the heating of a completely pre-alloyed powder to a temperature between the solid and liquid phase line of the alloy phase diagram, resulting in the promotion of particle rearrangement and solid phase re-dissolution. Thus, the sintered part is densified rapidly and shows a much higher density than that of the solidus-sintered part [22].

\section{Densification}

The effect of sintering time on the sintered densities of the samples sintered at 1270,1280, and $1300{ }^{\circ} \mathrm{C}$ are shown in Figure 4 . This shows that under the same holding time, the density increases with an increase in the temperature. At $1270{ }^{\circ} \mathrm{C}$, the maximum density is $7.39 \mathrm{~g} / \mathrm{cm}^{3}$ for $5 \mathrm{~h}$, and fur-

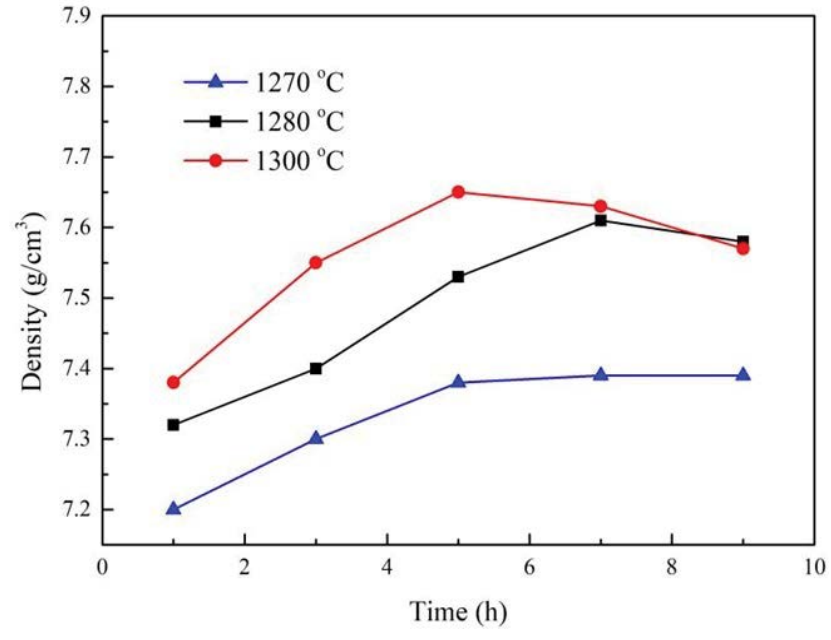

Figure 4: Sintered-density curves obtained by sintering at three temperatures and holding times.

ther holding does not improve the density. When the temperature increases to 1280 and $1300{ }^{\circ} \mathrm{C}$, the density increases obviously to above $7.6 \mathrm{~g} / \mathrm{cm}^{3}$, which is attributable to the liquid phase appearing at this temperature range. For $1280^{\circ} \mathrm{C}$, the highest density is achieved when the holding time is $7 \mathrm{~h}$, and further holding leads to a slightly lower density, indicating the possibility of over-heating. Furthermore, the best holding time for $1300{ }^{\circ} \mathrm{C}$ is only 5 h. A higher temperature creates more liquid phase but accelerates the grain growth and over-heating. These harmful effects are more significant when the holding time is longer.

\section{Microstructure}

The microstructures of the samples sintered at $1280{ }^{\circ} \mathrm{C}$ for 5,7 , and $9 \mathrm{~h}$ are shown in Figure 5, and the average grain sizes of the samples are 45, 64, and $76 \mu \mathrm{m}$, respectively. This shows that with the increase in the holding time, the number of spherical pores gradually decreases; the pores become smaller, and the grains grow. For the $9 \mathrm{~h}$ sample, the pores are more likely to be found inside the grain. The grain boundary coarsening took place at $9 \mathrm{~h}$ when the sintered density decreased. Sintering at $1300{ }^{\circ} \mathrm{C}$ led to local over-heating or over-burning, as shown in Figure 6. Significant grain growth was observed. Additionally, the grain boundary was coarsened by the excess liquid phase. Such a structure weakens the bonding strength among grains. If the intergranular gap is big enough, the density decreases slightly.

\section{Mechanical properties and fracture surface}

Figure 7 shows the micro-hardness, tensile 


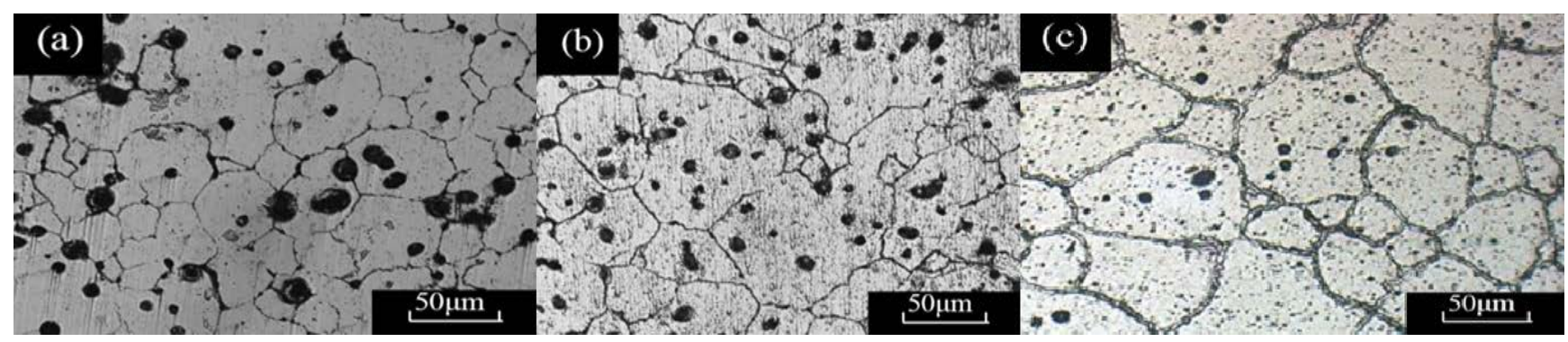

Figure 5: Microstructures of SS samples sintered at $1280^{\circ} \mathrm{C}$ for a) $5 \mathrm{~h}$; b) $7 \mathrm{~h}$; and c) $9 \mathrm{~h}$.

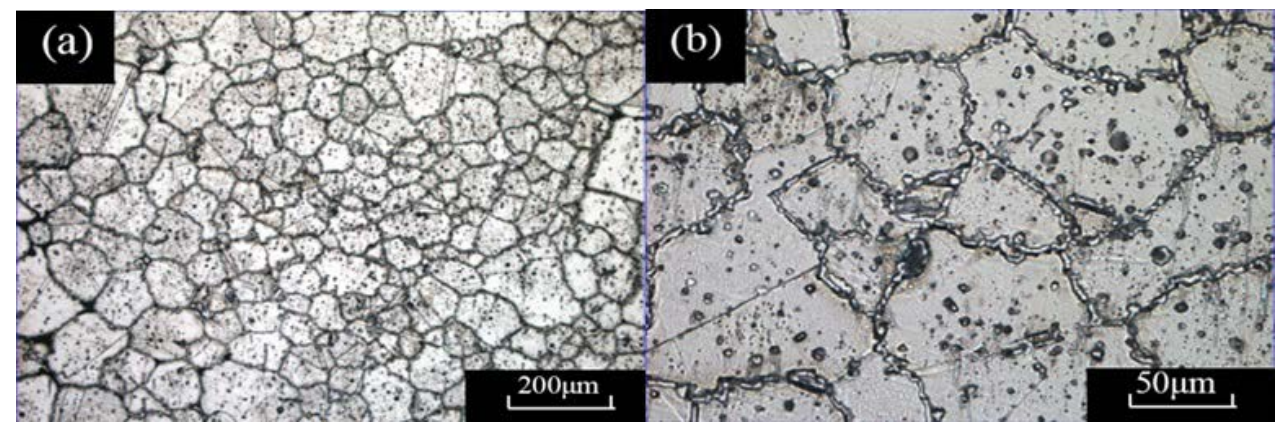

Figure 6: Microstructure of SS samples sintered at $1300{ }^{\circ} \mathrm{C}$ for $7 \mathrm{~h}$ : a) Over-heated microstructure with coarse grain boundary; and b) Over-burned microstructure with a melting zone in the grain boundary.

strength, and elongation of the samples sintered at 1280 and $1300{ }^{\circ} \mathrm{C}$ with different holding times. The best properties are achieved upon sintering at $1300{ }^{\circ} \mathrm{C}$ for $5 \mathrm{~h}$ or $1280^{\circ} \mathrm{C}$ for $7 \mathrm{~h}$, and the change trends of the micro-hardness, tensile strength, and elongation are consistent with that of the sintering density when prolonging the holding time. Initially, a higher density leads to a lower porosity and an enhanced bonding strength between the powder particles. Then, the properties are degraded because of grain growth and a weaker grain boundary.

The samples sintered at $1300{ }^{\circ} \mathrm{C}$ for $5 \mathrm{~h}$ show a higher density, strength, and hardness than those sintered at $1280{ }^{\circ} \mathrm{C}$ for $7 \mathrm{~h}$, but the elongation is slightly lower. However, this sintering was carried out in a lab sintering furnace with a small chamber. When sintering is carried out in an industrial furnace with a bigger chamber, a larger temperature gradient is expected and the risks of over-burning and over-heating increase. In addition, the samples sintered at a lower temperature show more stable mechanical properties, as shown in Figure 7. Therefore, a lower temperature is recommended.

The fracture morphologies of the samples sintered for different holding times are shown in Figure 8 . All the samples are dimple fractured, which indicates that all the samples belong to the ductile fracture-type. A dimple is the microvoid produced by the plastic deformation of material in the range of a microzone, which could be used as a proxy of the ductility. The sample sintered for $5 \mathrm{~h}$ shows residual pores, which degrade the ductility. As shown in Figure 8b, the sample sintered for $7 \mathrm{~h}$ has coarser but deeper dimples; therefore, its ductility is the best. A longer holding time of $9 \mathrm{~h}$ leads to lesser and shallower dimples; hence, the ductility decreases obviously. Crack propagation is easier in a structure with weak grain bonding. Therefore, although the sample sintered at $9 \mathrm{~h}$ is almost equivalent to that sintered at $7 \mathrm{~h}$, the elongation is much lower.

\section{Conclusions}

1. The optimum sintering conditions for MIM HK30 SS are $1280{ }^{\circ} \mathrm{C}$ and a holding time of $7 \mathrm{~h}$. At this temperature, a supersolidus liquid sintering effect is achieved, which promotes sintering. A higher sintering temperature or longer sintering time may decrease the density.

2. The average grain sizes of the samples are 45 , 64, and $76 \mu \mathrm{m}$ after sintering at $1280{ }^{\circ} \mathrm{C}$ for 5 , 7 , and $9 \mathrm{~h}$, respectively. With an increase in the sintering temperature, the grains grow and the grain boundaries coarsen; over-heating or over-burning takes place. 
3. Using the optimum sintering process, the density is $7.61 \mathrm{~g} / \mathrm{cm}^{3}$, the micro-hardness is $187 \mathrm{HV}_{1.0^{\prime}}$ the tensile strength is $570 \mathrm{MPa}$, and the elonga- tion is $31 \%$, attaining the performance index of forged material.
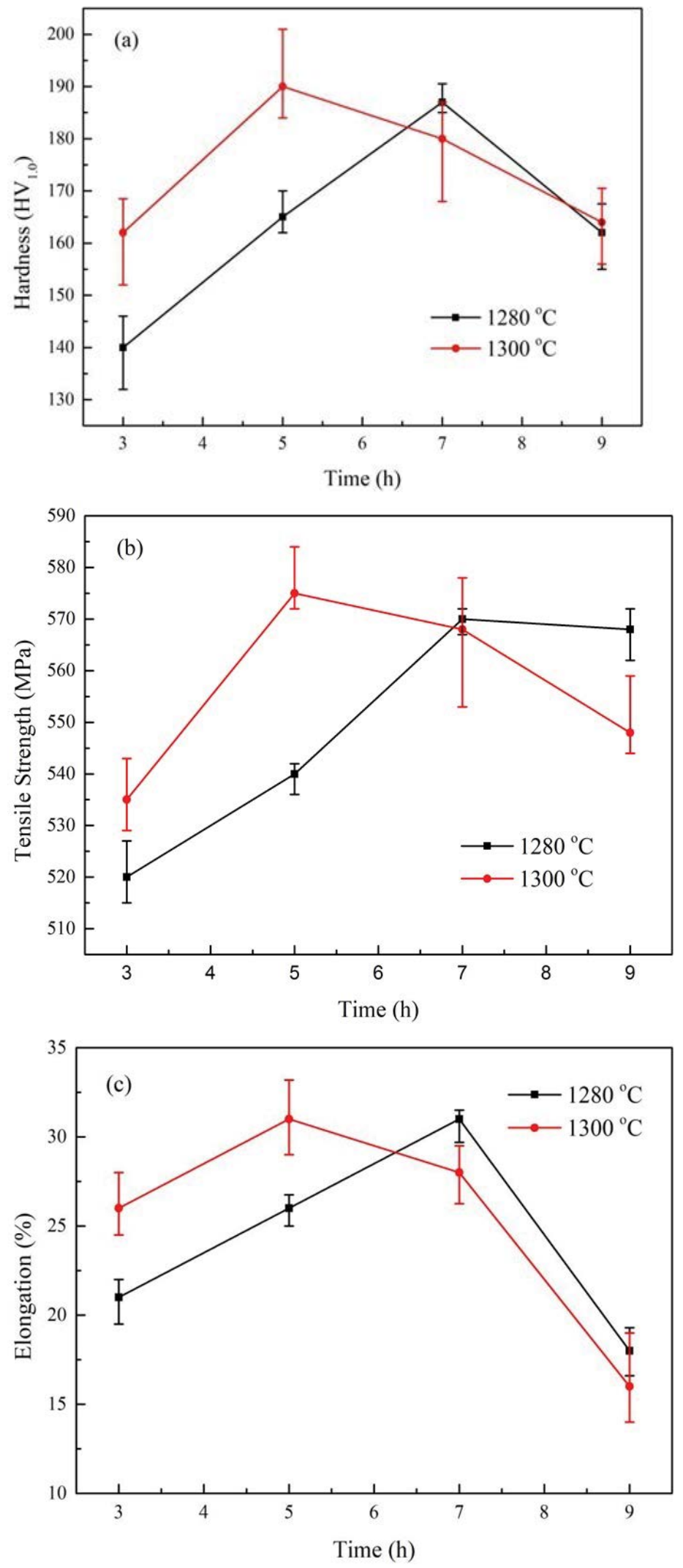

Figure 7: Mechanical properties of SS samples sintered at 1280 or $1300^{\circ} \mathrm{C}$ with different holding times: a) Micro-hardness; b) Tensile strength; and c) Elongation. 


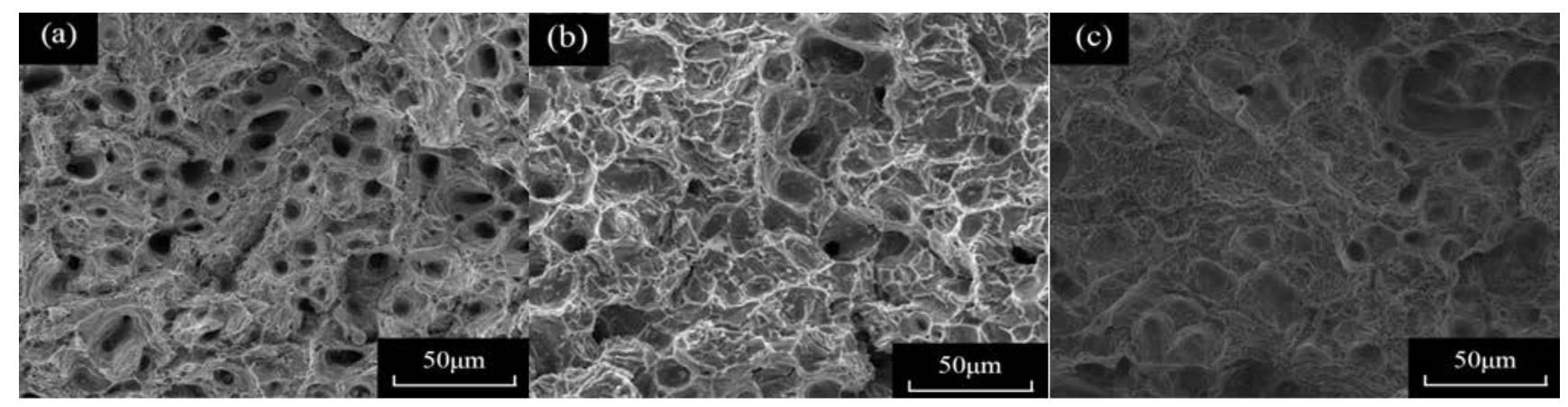

Figure 8: Fracture morphology of SS samples sintered at $1280^{\circ} \mathrm{C}$ with a holding time of a) $5 \mathrm{~h}$; b) $7 \mathrm{~h}$; and c) $9 \mathrm{~h}$.

\section{Acknowledgement}

The authors acknowledge support from the Hunan Provincial Natural Science Foundation (Grant No. 2018JJ3507), the Guangxi Science and Technology Plan Project (Grant No. AD16380019), and the China Postdoctoral Science Foundation (Grant No. 2018M632978).

\section{References}

1. J Lou, Y Li, H He, D Li, G Wang, et al. (2017) Interface development and numerical simulation of powder co-injection moulding. Part. I. Experimental results on the flow behaviour and die filling process. Powder Technology 305: 405-410.

2. J Lou, Y Li, H He, D Li, G Wang, et al. (2017) Interface development and numerical simulation of powder co-injection moulding. Part II. Numerical simulation and experimental verification. Powder Technology 305: 357-363.

3. S Islam, S Samanta, Nagahanumaniah, H Roy, Aditya Kumar Lohar, et al. (2018) Rheological behavior of $316 \mathrm{~L}$ stainless steel feedstock for $\mu$-MIM. Materials Today: Proceedings 5: 8152-8158.

4. R Machaka, P Ndlangamandla, M Seerane (2018) Capillary rheological studies of 17-4 PH MIM feedstocks prepared using a custom CSIR binder system. Powder Technology 326: 37-43.

5. S Ani, A Muchtar, N Muhamad, Jaharah A Ghani (2014) Binder removal via a two-stage debinding process for ceramic injection molding parts. Ceramics International 40: 2819-2824.

6. M Kearns, T Tingskog, A Coleman, Keith Murray, Viacheslav Ryabinin, et al. (2014) A study of microstructure and mechanical properties of metal injection moulded HK-30. PM World Congress, Orlando, USA.

7. M Yousefi, M Farghadin, A Farzadi (2015) Investigate the causes of cracks in welded 310 stainless steel used in the Flare tip. Engineering Failure Analysis 53: 138-147.
8. M Khan, Q Wang (2013) Investigation of crack initiation and propagation behavior of AISI 310 stainless steel up to very high cycle fatigue. International Journal of Fatigue 54: 38-46.

9. A Bhrami, A Ashrafi, SM Rafiaei, MY Mehr (2017) Sigma phase-induced failure of AISI 310 stainless steel radiant tubes. Engineering Failure Analysis 82: 56-63.

10.H Sun, Y Sun, R Zhang, M Wang, R Tang, et al. (2015) Study on hot workability and optimization of process parameters of a modified 310 austenitic stainless steel using processing maps. Materials and Design 67: 165-172.

11.V Micanek, G Agnew, N Morand, J Musil, F Abel (2017) Exhaust gas variable turbine assembly. United States patent application, USA.

12.K Martin, P Davies (2007) Review of the MIM industry: Recent trends in powder size and composition. Advances in Powder Metallurgy and Particulate Materials 1: 04.

13.H He, J Lou, Y Li, Hao Zhang, Shuai Yuan, et al. (2018) Effects of oxygen contents on sintering mechanism and sintering-neck growth behaviour of $\mathrm{Fe} \mathrm{Cr}$ powder. Powder Technology 329: 12-18.

14.R Enneti, S Park, R German, SV Atre (2012) Review: Thermal debinding process in particulate materials processing. Advanced Manufacturing Processes 27: 103-118.

15.RM German, SV Atre, T Kang, S Ahn, S Chung, et al. (2012) Handbook of Metal Injection Molding. Woodhead publishing in materials.

16.MPIF (2007) Materials standards for PM structural parts. Metal Powder Industries Federation.

17.W Wang (2015) PIM advanced materials \& applications 1: Metal injection moulding of heat and wear resistant alloy DIN1. 4091. European congress and exhibition on powder metallurgy. European PM Conference Proceedings, The European Powder Metallurgy Association. 
18. H Shen, Y Li, C Liu, HE Hao (2013) Effect of Ti on mechanical performance and dimensional stability of MIM HK30 stainless steel. Materials Science and Engineering of Powder Metallurgy 18: 45-52.

19.D Li, H He, Y Li, X Zhang (2013) Effect of Ti addition on sintering densification of MIM HK30 stainless steel. Journal of Central South University 44: 3151-3158.

20.H Zhang, H He, Y Li, X Zhang (2017) Effect of carbon content on microstructure and mechanical properties of metal injection molded HK30 stainless steel.
Materials Science and Engineering of Powder Metallurgy 22: 739-746.

21.(2004) Standard test methods for determining average grain size. ASTM International.

22.K Kudo, S Wai, T Osada, F Tsumori, H Miura (2016) Improvement of mechanical properties of injection molded Ni-base superalloy compacts. Journal of the Japan Society of Powder \& Powder Metallurgy 63: 462-467. 